\title{
Total ozone retrieval from GOME UV spectral data using the weighting function DOAS approach
}

\author{
M. Coldewey-Egbers, M. Weber, L. N. Lamsal, R. de Beek, M. Buchwitz, and J. P. Burrows \\ Institute of Environmental Physics, University of Bremen, Bremen, Germany \\ Received: 10 June 2004 - Published in Atmos. Chem. Phys. Discuss.: 31 August 2004 \\ Revised: 25 January 2005 - Accepted: 15 March 2005 - Published: 29 March 2005
}

\begin{abstract}
A new algorithm approach called Weighting Function Differential Optical Absorption Spectroscopy (WFDOAS) is presented which has been developed to retrieve total ozone columns from nadir observations of the Global Ozone Monitoring Experiment. By fitting the vertically integrated ozone weighting function rather than ozone crosssection to the sun-normalized radiances, a direct retrieval of vertical column amounts is possible. The new WFDOAS approach takes into account the slant path wavelength modulation that is usually neglected in the standard DOAS approach using single airmass factors. This paper focuses on the algorithm description and error analysis, while in a companion paper by Weber et al. (2004) a detailed validation with groundbased measurements is presented. For the first time several auxiliary quantities directly derived from the GOME spectral range such as cloud-top-height and cloud fraction $\left(\mathrm{O}_{2}\right.$-A band) and effective albedo using the Lambertian Equivalent Reflectivity (LER) near $377 \mathrm{~nm}$ are used in combination as input to the ozone retrieval. In addition the varying ozone dependent contribution to the Raman correction in scattered light known as Ring effect has been included. The molecular ozone filling-in that is accounted for in the new algorithm has the largest contribution to the improved total ozone results from WFDOAS compared to the operational product. The precision of the total ozone retrieval is estimated to be better than $3 \%$ for solar zenith angles below $80^{\circ}$.
\end{abstract}

\section{Introduction}

The GOME (Global Ozone Monitoring Experiment) onboard the ERS-2 satellite is the first European experiment dedicated to global ozone measurements (Burrows et al., 1999a).

Correspondence to: M. Coldewey-Egbers

(coldewey@iup.physik.uni-bremen.de)
It measures the solar light from $240-790 \mathrm{~nm}$ in nadir viewing geometry, that is reflected and scattered by the earthatmosphere system, and the solar irradiance. The spectral resolution varies from $0.2 \mathrm{~nm}$ (UV) to $0.4 \mathrm{~nm}$ (VIS). In the relevant region for total ozone retrieval $(320-340 \mathrm{~nm})$ the spectral resolution is about $0.17 \mathrm{~nm}$.

The satellite moves in a retrograde, sun-synchronous, near polar orbit at a height of around $795 \mathrm{~km}$. The maximum scan width in the nadir viewing is $960 \mathrm{~km}$ and global coverage is achieved within three days. One across track scan sequence consists of four ground pixel types with $1.5 \mathrm{~s}$ integration time each. Each ground pixel is $320 \mathrm{~km}$ across track by $40 \mathrm{~km}$ along track. On selected days smaller swath widths (3 days per month) or static nadir positions (1 day per month) are used. Regular measurements are available since July 1995. From June 2003 the GOME coverage is limited to the EuroAtlantic sector stretching from Canada to Russia due to the failure of the tape recorder for intermediate data storage.

The GOME instrument together with the Total Ozone Mapping Spectrometer (TOMS) since 1979 provide a valuable longterm dataset with near global coverage for ozone trend assessment (Bodeker et al., 2001; Fioletov et al., 2002). However, differences in algorithm and instrument design (for both satellite and ground instruments) can lead to instrumental artifacts in trend calculation without homogenisation of combined datasets (Bodeker et al., 2001). This will remain an important issue when the current generation of total ozone satellite instruments are being succeeded by new instruments such as SCIAMACHY/ENVISAT (launched in 2002), OMI (launched in July 2004) and the three GOME2 aboard Metop (first launch 2006)(Bovensmann et al., 1999; Stammes et al., 1999).

The operational total ozone retrieval GOME Data Processor Version 3.0 (GDP V3.0) shows some shortcomings when comparing satellite data with ground-based data. A seasonal cycle and variations with solar zenith angle can be observed (GDP V3 VALREPORT). The standard DOAS method is

(C) 2005 Author(s). This work is licensed under a Creative Commons License. 
used and slant columns derived from a spectral fit have to be converted into vertical columns using airmass factors at a single wavelength. This approach assumes that the absorber is weak and the atmosphere optically thin. Ozone in the Huggins band, however, shows significant absorption so that this basic assumption is violated.

In this study a more generalized approach, called Weighting Function DOAS (WFDOAS) has been introduced. It has been first demonstrated to be applicable to trace gas column retrieval in the near infrared region of SCIAMACHY (Scanning Imaging Absorption Spectrometer for Atmospheric Chartography) (Buchwitz et al., 2000). A direct retrieval of vertical ozone amounts is possible as the slant path wavelength modulation is taken into account. First results seem to indicate its promising potential (Coldewey-Egbers et al., 2004).

In a companion paper (Weber et al., 2004) the new algorithm has been extensively validated against ground-based measurements from the World Ozone and UV Radiation Data Center. From the global analysis excellent agreement between WFDOAS results and ground data was found.

In Sects. 2 and 3 the theoretical background of the algorithm and the retrieval scheme are described. The Ring effect and its influence on the total ozone retrieval using WFDOAS are investigated in Sect. 4. This is a very important aspect since systematic errors on the order of a few percent occur, when the molecular ozone filling-in due to the Ring effect is not accounted for. In Sect. 5 we discuss two case studies (tropics and mountains), that demonstrate the proper working of the effective height concept (see Section 3.1). As an example how well the new algorithm is working, a comparison with ground data from Hohenpeissenberg (Germany) is shown in Sect. 6, where also the differences of WFDOAS compared to the GDP V3.0 are analysed using one selected GOME orbit. Section 7 contains a summary of the various error sources that contribute to the overall error of the retrieved ozone column. A global error budget is derived.

\section{Algorithm description}

The measured atmospheric optical depth is approximated by a Taylor expansion around the reference intensity plus a loworder polynomial. The total column information is obtained only from differential trace gas absorption structures. The cubic polynomial $P_{i}$ accounts for all broadband contributions such as surface albedo and aerosol.

The optical depth equation can be written as follows:

$$
\begin{aligned}
\ln I_{i}^{\text {mea }}\left(V^{t}, \boldsymbol{b}^{t}\right) \approx & \ln I_{i}^{\text {mod }}(\bar{V}, \overline{\boldsymbol{b}}) \\
& +\left.\frac{\partial \ln I_{i}^{\text {mod }}}{\partial V}\right|_{\bar{V}} \times(\hat{V}-\bar{V}) \\
& +\left.\frac{\partial \ln I_{i}^{\text {mod }}}{\partial T}\right|_{\bar{T}} \times(\hat{T}-\bar{T}) \\
& +S C D_{\mathrm{NO}_{2}} \cdot \sigma_{i, N O_{2}}
\end{aligned}
$$

$$
\begin{aligned}
& +S C D_{\text {BrO }} \cdot \sigma_{i, \text { BrO }} \\
& +S C D_{\text {Ring }} \cdot \sigma_{i, \text { Ring }} \\
& +S C D_{\text {usamp }} \cdot \sigma_{i, \text { usamp }} \\
& +P_{i}
\end{aligned}
$$

$I^{\text {mea }}$ is the measured intensity and $I^{\text {mod }}$ the sunnormalized reference intensity as provided by the radiative transfer model. Index $t$ denotes the true atmospheric state. The entire right-hand side of the equation (excluding the reference intensity) has to be adjusted to the measured intensity (left-hand side) for all spectral points (index $i$ ) simultaneously. $\bar{V}$ is the reference ozone column corresponding to the reference intensity, and $\bar{T}$ is the reference surface temperature. $\hat{V}$ and $\hat{T}$ denote the corresponding fit parameters. The Ring effect $\left(\sigma_{i, \text { Ring }}\right)$ and the under-sampling spectrum $\left(\sigma_{i, \text { usamp }}\right)$ (Slijkhuis et al., 1999) are treated as effective absorbers similar to the approach used in standard DOAS. Fitting the slant column density ( $S C D$ ) is also applied to the minor absorbers $\mathrm{NO}_{2}$ and $\mathrm{BrO}$. The unknown fit parameters are derived using a linear least-squares minimization. The retrieved scalar temperature correction $\Delta T=\hat{T}-\bar{T}$ actually represents a shift in the entire vertical temperature profile. It effectively accounts for the dependence of the observed ozone absorption on stratospheric temperature. Since the ozone and temperature weighting function correlate, the independent retrieval of both parameters will lead to errors in fitted ozone vertical column. They are expected to be well below $2 \%$ for solar zenith angles below $80^{\circ}$ (see also Sect. 7).

The main difference between the WFDOAS algorithm and the standard DOAS is the use of wavelength dependent weighting functions $\left(\partial \ln I_{i}^{\text {mod }} / \partial V\right.$ and $\left.\partial \ln I_{i}^{\bmod } / \partial T\right)$ instead of absorption cross-sections and airmass factors. Weighting functions describe the relative radiance change due to a vertical profile change assuming an altitude independent scaling factor.

A large set of reference spectra has been constructed, which includes nearly all possible atmospheric conditions. The radiance spectra and weighting functions are computed as a function of total ozone including profile shape, solar zenith angle, line-of-sight, relative azimuth angle, surface albedo, and altitude. Table 1 gives an overview of the parameter space. Ozone and temperature profiles are taken from TOMS V7 (Total Ozone Mapping Spectrometer Version 7) climatology (Wellemeyer et al., 1997) which contains different profile shapes for three latitude belts (low, middle and high) as a function of the total ozone column. The dependence of the relative azimuth angle on solar zenith angle and line-of-sight has been obtained using all GOME orbits from 1998. The minimum, maximum, and mean angles are taken for reference spectra calculation for a given combination of solar zenith angle and line-of-sight. The altitude of the lower boundary of the atmosphere varies between 0 and $12 \mathrm{~km}$. In the actual retrieval this altitude is chosen according to ground height, cloud height, and cloud fraction (see Sect. 3.1). 
All reference spectra have been computed with the SCIATRAN/CDI code, an extension of the GOMETRAN++ radiative transfer model (Rozanov et al., 1997, 1998) in the pseudo-spherical approximation. It was specifically developed for simulation of back-scattered intensities and is based on the finite differences approach. The viewing angles lineof-sight and solar zenith angle are taken at the ground level for this computation. Compared to the full spherical mode, the use of ground level viewing geometry (line-of-sight, solar zenith angle and relative azimuth) rather than top-ofatmosphere viewing geometry in the pseudo-spheric approximation leads to lower slant column errors even for large swath widths of up to $\pm 45^{\circ}$ (de Beek et al., 2004). But this very special case of the polar view mode is excluded from our analysis.

The shift and squeeze operation to improve the wavelength misregistration between the different spectra is limited to the earthshine spectrum, which is fitted to the GOME solar spectrum. Following the recommendation of Roozendael et al. (2003), a constant shift of $+0.017 \mathrm{~nm}$ has been applied to GOME FM cross sections for ozone and nitrogen dioxide (Burrows et al., 1998, 1999b) before the calculation of reference spectra and weighting functions. In order to correct for the Doppler shift $(+0.008 \mathrm{~nm})$ in the solar reference and for wavelength calibration errors using the onboard $\mathrm{Pt} / \mathrm{Ne} / \mathrm{Cr}$ hallow cathode lamp, the GOME solar spectrum is nonlinearly fitted to a high resolution solar atlas derived from Fourier transform spectrometer measurements carried out with the McMath Solar Telescope, Kitt Peak Observatory, Arizona (Kurucz et al., 1984). This so-called Fraunhofer fitting is done before the DOAS fit is performed.

We selected the $8.2 \mathrm{~nm}$ wide fit window from 326.8 $335.0 \mathrm{~nm}$ for ozone retrieval. These boundaries were mainly determined by the correlation coefficient between ozone and temperature weighting functions, that should be minimized to retrieve both parameters independently. The correlation decreases the wider the fit window is, but on the other hand fit residuals then increase. Towards larger wavelengths the temperature dependence of ozone cross sections inceases, but ozone absorption gets smaller. The balance between the various requirements led to the current choice of the fitting window.

In case of cloud contaminated ground pixels, the part of the ozone column, which is below the top of the clouds, cannot be detected by the satellite. This ghost vertical column (GVC) has to be estimated from climatological vertical ozone profiles and is added to the vertical column retrieved from the spectral fit. The GVC is computed by integrating the profile from surface pressure up to the cloud top pressure. Partial cloudiness can be taken into account by multiplying the integrated column with fractional cloud cover from FRESCO (Fast Retrieval Scheme for Clouds from the
Table 1. Parameter space of the look-up-tables.

\begin{tabular}{lcccc}
\hline Atmospheric Parameter & Min & Max & $\Delta$ & $\mathrm{N}$ \\
\hline Total Ozone (high latitudes) & $125 \mathrm{DU}$ & $575 \mathrm{DU}$ & $50 \mathrm{DU}$ & 10 \\
Total Ozone (mid latitudes) & $125 \mathrm{DU}$ & $575 \mathrm{DU}$ & $50 \mathrm{DU}$ & 10 \\
Total Ozone (low latitudes) & $225 \mathrm{DU}$ & $475 \mathrm{DU}$ & $50 \mathrm{DU}$ & 6 \\
\hline Solar Zenith Angle & $15^{\circ}$ & $92^{\circ}$ & $5^{\circ}$ if SZA $\leq 70^{\circ}$ & 34 \\
& & & $1^{\circ}$ if SZA $>70^{\circ}$ & \\
\hline Line-Of-Sight & $-34.5^{\circ}$ & $34.5^{\circ}$ & $11.5^{\circ}$ & 7 \\
Relative Azimuth Angle & $\left(^{*}\right)$ & $\left(^{*}\right)$ & & 3 \\
\hline Surface Albedo & 0.02 & 0.98 & $\sim 0.2$ & 6 \\
Altitude & $0 \mathrm{~km}$ & $12 \mathrm{~km}$ & $2 \mathrm{~km}$ & 7 \\
\hline
\end{tabular}

(*) Min/max of relative azimuth angle depend on SZA and LOS.

Oxygen A-Band)(Koelemeijer et al., 2001) as follows:

$G V C=f \cdot \int_{h^{\prime}=h_{o}}^{h_{c l d}}\left[\mathrm{O}_{3}\left(h^{\prime}\right)\right] d h^{\prime}$.

$f$ and $h_{c l d}$ are the fractional cloud cover and cloud-topheight retrieved with FRESCO, respectively. $h_{o}$ is the surface height of the GOME scene and $\left[\mathrm{O}_{3}(h)\right]$ the ozone concentration at altitude $h$. For the integration of the tropospheric column up to the cloud-top-pressure, ozone profiles from the TOMS V8 monthly and zonal mean climatology (G. Labow, personal communication) are used. This climatology was compiled from ozone sonde data, SAGE II, and POAM III satellite data in the 90s (G. Labow, personal communication). The latter climatology takes hemispherical (ten degree latitude steps) and seasonal differences (monthly mean) into account, and is therefore a much better representation of the troposphere, since biomass burning and enhanced pollution events are generally seasonal dependent and to a large extent independent of the stratospheric variability. A total ozone dependent profile climatology like the TOMS V7 climatology or the more recent IUP climatology (Lamsal et al., 2004) are better suited for defining reference scenarios and weighting functions. They better represent the stratospheric variability, because of possibly large day-to-day changes in stratospheric ozone column, that are not accounted for by a monthly and zonal mean climatology. Figure 1 shows and summarises the schematics of the GVC determination.

\section{Retrieval Scheme}

This section describes the retrieval scheme of the WFDOAS algorithm. As input for the retrieval the following data and information are required.

- Calibrated GOME level 1 radiance spectrum and GOME solar data from the same day 


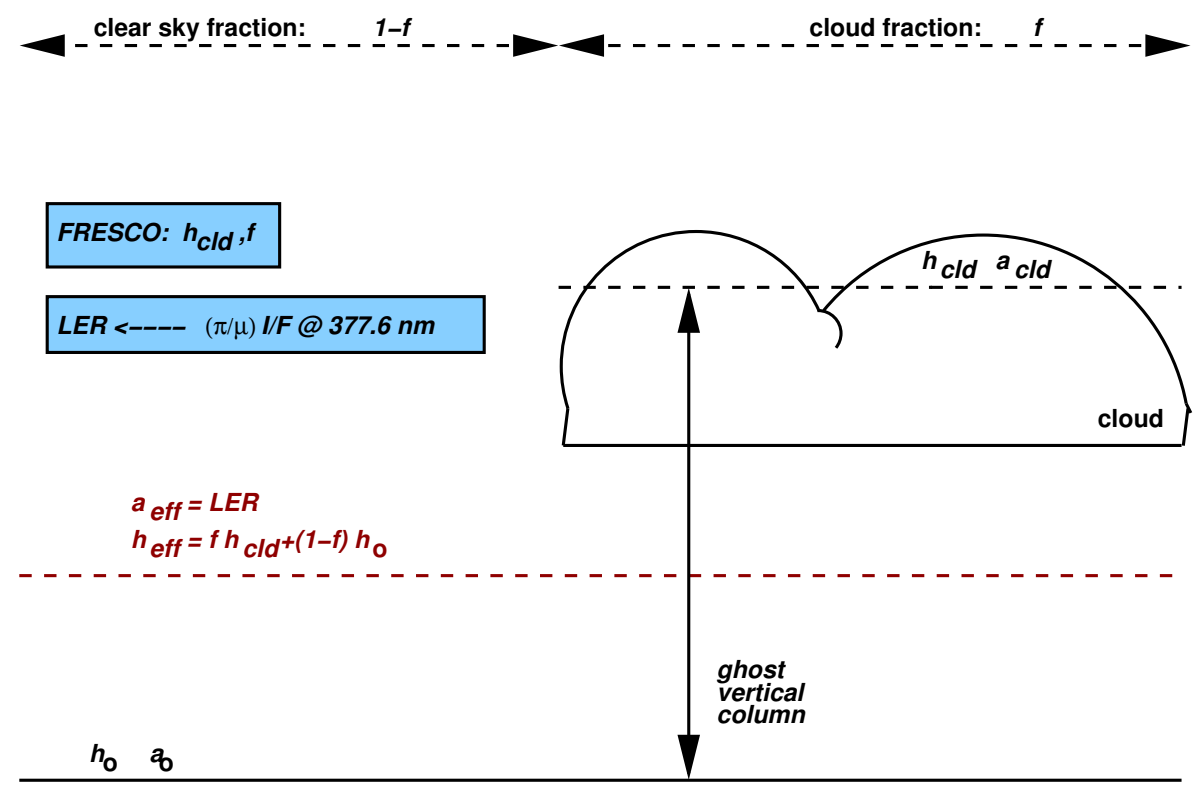

ground/surface

Fig. 1. Definition of various parameters defined for cloud retrieval from GOME using FRESCO (Koelemeijer et al., 2001) and the ozone ghost vertical column correction. Cloud fraction $f$ and cloud top height $h_{c l d}$ are retrieved from the oxygen A band absorption assuming a constant cloud albedo $\left(a_{c l d}=0.8\right)$. Surface albedo $a_{o}$ near $760 \mathrm{~nm}$ is taken from a 5-year GOME database (Koelemeijer et al., 2003). The effective UV albedo $a_{e f f}$ is determined using the Lambertian equivalent reflectivity approach near $377 \mathrm{~nm}$ (see text). The effective scene height $h_{\text {eff }}$ is then calculated from the weighted average of cloud-top-height $h_{c l d}$ and surface height $h_{o}$ weighted by the cloud fraction $\left(h_{e f f}=f \cdot h_{c l d}+(1-f) \cdot h_{o}\right)$. The ghost vertical column (GVC) is determined by integrating a climatological profile from surface to the retrieved cloud-top-height and then multiplying the integrated sub-column by the cloud fraction (see text for details).

- GOME ground pixel geolocation information (latitudes and longitudes of pixel center and corners of footprint)

- GOME satellite viewing geometry (solar zenith angle, line-of-sight, and relative azimuth angle) that are converted to ground scene viewing geometry

- A priori value for total ozone column (from TOMS V8 monthly mean zonal climatology)

- effective altitude which is obtained from the oxygen Aband with FRESCO (see text)

- effective albedo, which is obtained from GOME level 1 radiance and irradiance data near $377 \mathrm{~nm}$ (see text)

\subsection{Retrieval of effective altitude and scene albedo}

Effective height is obtained from FRESCO. This algorithm derives the cloud top height and the cloud fraction from the oxygen transmittance assuming a high reflecting boundary representing the cloud top. The surface albedo is taken from minimum spectral reflectances derived from a five year GOME data record (Koelemeijer et al., 2003). The cloud top albedo is fixed to a value of 0.8 . The effective height for the GOME ground pixel is a weighted sum of the ground altitude $\left(h_{o}\right)$ and the retrieved cloud top height $\left(h_{c l d}\right)$ weighted by the fractional cloud cover $(f)$ as shown in Fig. 1. Surface pressure and cloud top pressure are converted into altitudes using the US standard atmosphere before GVC integration. In the snow and ice mode of FRESCO the effective altitude is the value which comes out as the effective altitude for the reflecting layer assuming total cloud coverage. The cloud discrimination only works if an albedo contrast between surface and cloud exists.

The Lambertian Effective Reflectivity (LER)(Herman and Celarier, 1997; Koelemeijer et al., 2003) defines the effective albedo and is obtained from GOME sun-normalized radiance at $377.6 \mathrm{~nm}$. At this wavelength atmospheric absorption is minimum, and the variation with respect to the Ring effect is very small and can be corrected easily. A look-up table of pre-calculated sun-normalized radiances in an aerosol free atmosphere as a function of solar zenith angle, line-of-sight, relative azimuth angle, ground altitude, and surface albedo at this wavelength has been generated. As altitude input serves the effective height as derived from FRESCO. For this set of parameters, radiances as a function of albedo are extracted from the table. The effective albedo is then obtained by a bi-sectional search along this curve. The use of the LER in the ozone retrieval represents, to a certain extent, a first order aerosol correction, except for absorbing aerosols that may prevent ozone below the aerosol layer from being detected (see also Sect. 7). 

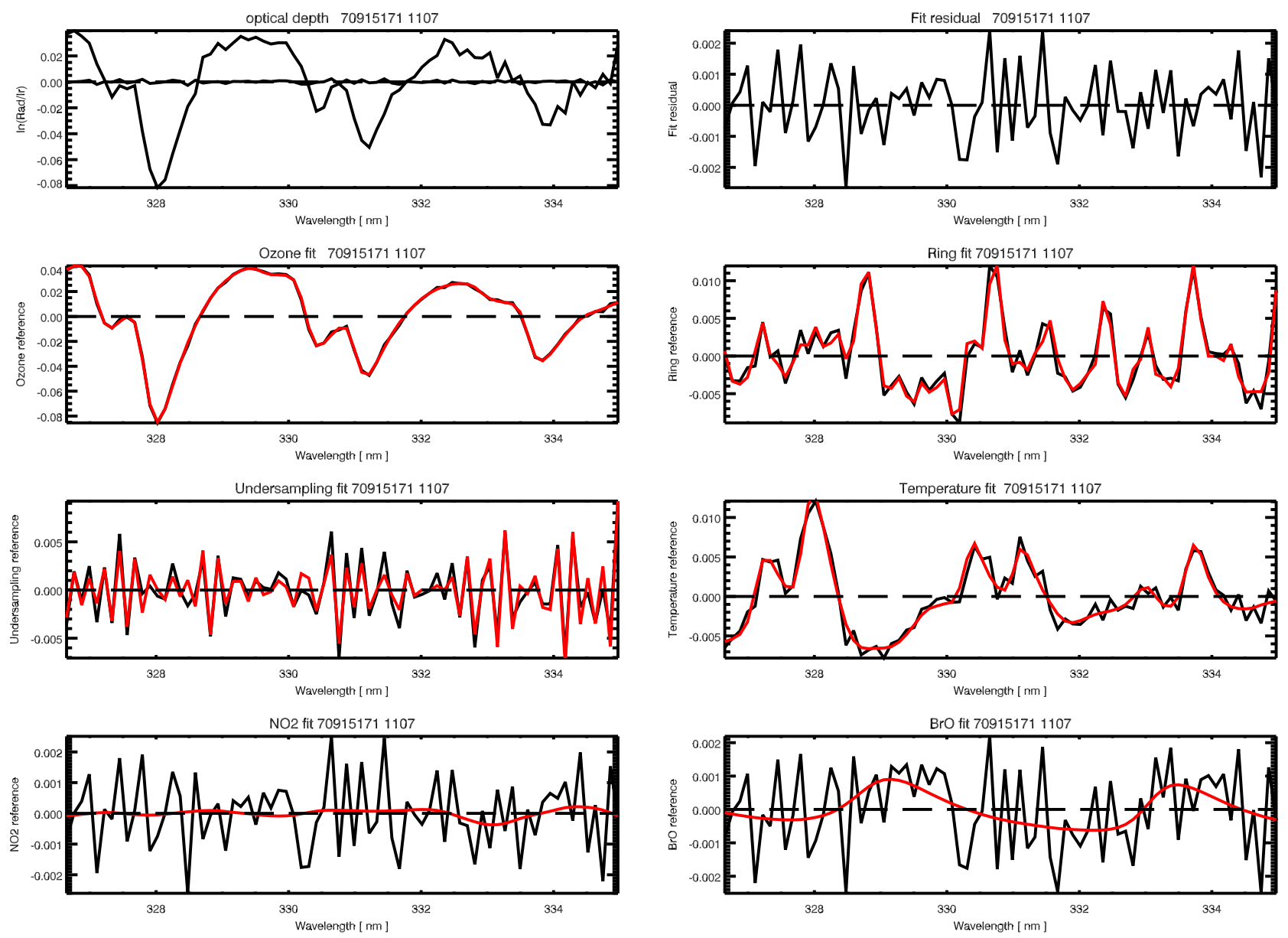

Fig. 2. Fit residual of pixel number 1107 (tropics) in GOME orbit 70915171. The GOME observed differential optical depth (left) and fit residual (left and right) are shown in the two top panels. The lower panels show the magnitude of the various terms in the WFDOAS equation. Red lines show the modeled values and the fit residual has been added to each term (black) to visualize the relative magnitude of the measurement noise. The following terms are shown in the lower panels from top to bottom and left to right: ozone, Ring, undersampling correction, temperature shift, $\mathrm{NO}_{2}$, and $\mathrm{BrO}$. The fit RMS is on the order of 0.001 .

\subsection{WFDOAS fitting procedure}

The algorithm contains an iterative scheme to retrieve total ozone. The first step is to find the nearest neighbour reference scenario. As a first guess the scenario which most closely matches the vertical column derived from the TOMS V8 monthly mean climatology is selected. Linear interpolation between effective albedo, effective altitude and relative azimuth angle is performed to obtain the closest reference.

The latitude $\phi$ of the pixel center defines from which latitude band (high, mid, or low) the ozone profiles will be taken for the fit. If $|\phi|>65^{\circ}$ high latitude profiles are selected, if $55^{\circ}>|\phi|>35^{\circ}$, mid latitude profiles are taken and if $|\phi|<25^{\circ}$, profiles come from low latitudes. In four ten degree wide transition regions $\left( \pm 55^{\circ}\right.$ to $\pm 65^{\circ}$ and $\pm 25^{\circ}$ to $\left.\pm 35^{\circ}\right)$ a linear interpolation between the reference spectra from high and mid latitudes, and from mid and low latitudes, respectively, is performed. The transition from one region to the other becomes more smooth and abrupt jumps in the vertical columns are avoided. Without this interpolation between latitude bands, i.e. at $30^{\circ}$ and $60^{\circ}$, jumps of up to about $+1 \%$ from mid to low latitudes and $-2 \%$ from mid to high latitudes may occur.

The next step is to find the nearest Ring spectrum in the same manner. They have been calculated as a function of solar zenith angle, ozone, altitude, albedo, and latitude, but no interpolation will be performed as in the case of the reference spectra (see Sect. 4 for more details on the calculation of Ring spectra). After the spectral fitting the retrieved ozone column is compared with that of the reference scenario. The fit is repeated if a reference scenario can be found which is closer to the retrieved value. After the iteration stops the ghost vertical column is added to the retrieved column to obtain the final total ozone amount. Typical fit residuals are shown in Fig. 2, where the differential optical depth measured and modeled as well as the contribution of 

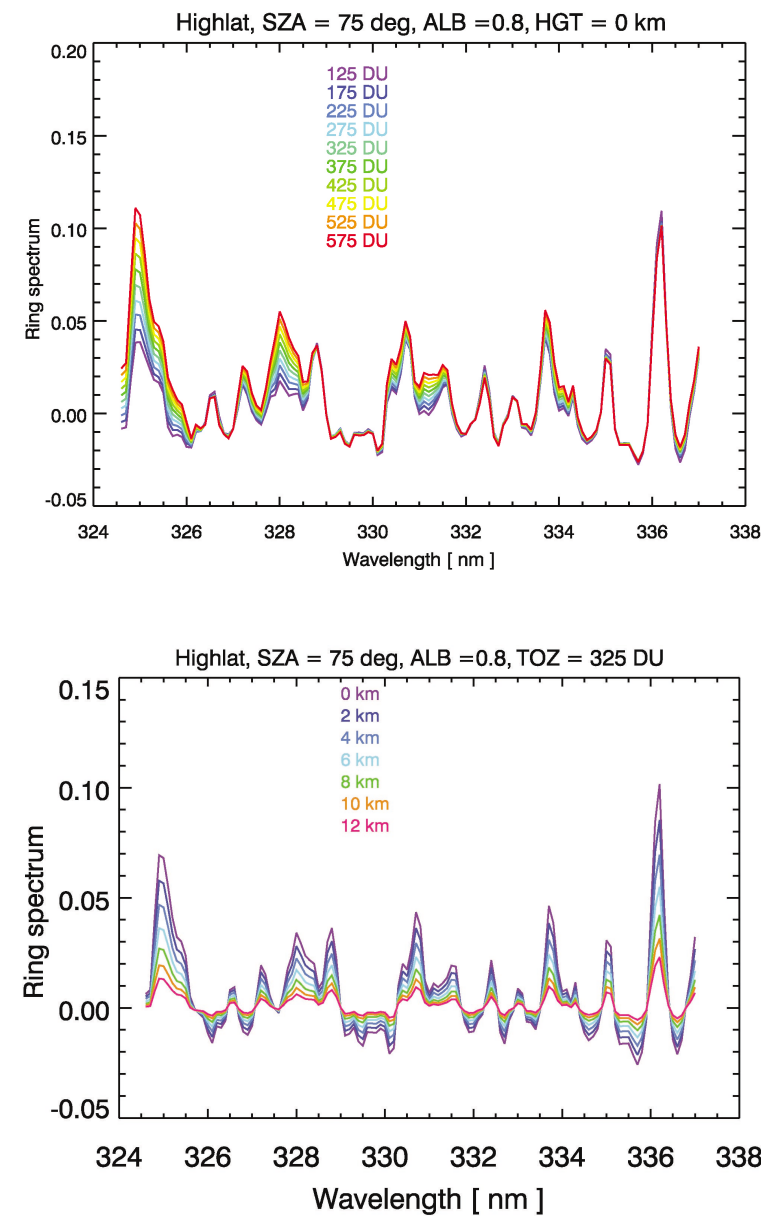

Fig. 3. SCIATRAN modeled Ring spectra using the high latitude TOMS V7 ozone profile climatology for different total ozone classes (top) and for a given ozone scenario as a function of altitude/effective height (bottom).

the individual terms in the DOAS equation are shown. $\mathrm{BrO}$ has in most cases negligible contributions except for those regions with enhanced tropospheric $\mathrm{BrO}$ (Richter et al., 1998). The RMS of the fit residuals is usually on the order of 0.001 , which is about half the typical values achieved in GDP V3.0.

\section{Ring effect and its implementation in WFDOAS}

Ground-based UV/vis instruments such as zenith-sky spectrometer and satellite instruments like GOME and TOMS observe the "filling-in" of solar Fraunhofer lines in the scattered light (Grainger and Ring, 1962). The dominant contribution to this effect is inelastic rotational Raman scattering (RRS) on air molecules (Kattawar et al., 1981) and is generally referred to as the Ring effect. Rotational Raman scattering has to be accounted for in ground based zenith-sky measurements (Solomon et al., 1987; Fish and Jones, 1995) and backscatter UV satellite measurements (Joiner and Barthia,
1995; Chance and Spurr, 1997; Vountas et al., 1998; Sioris and Evans, 1999) when retrieving trace gas columns from scattered light. The most common procedure is to use the socalled Ring spectrum, which is the optical depth difference of calculated intensities with and without the Ring effect, as an effective absorber in the standard DOAS retrieval (Solomon et al., 1987; Vountas et al., 1998). In the Huggins band the Ring spectrum has the largest contribution to the differential optical depth after ozone itself. This filling-in is usually strongest in those spectral regions where the modulation of intensities with wavelength is largest, for instance around the $\mathrm{Ca} \mathrm{II} \mathrm{h}$ and $\mathrm{k}$ Fraunhofer lines near $395 \mathrm{~nm}$. It is therefore plausible that in regions where ozone absorption contributes to the intensity modulation of scattered light (as in the Huggins band), a non-negligible ozone depenedent contribution to the molecular "filling-in" should be expected. For total ozone retrieved using GDP V3.0, errors of several percents were found because the varying ozone dependent contribution to rotational Raman scattering is not properly accounted for (Roozendael et al., 2003).

The variability of the Ring spectra as a function of total ozone (using the corresponding profile shape from TOMS V7 climatology) is largest near the absorption peaks of ozone as depicted in the top panel of Fig. 3 (compare this with Fig. 2). The largest contribution to the Raman scattering occurs in the Rayleigh layer near the surface and the Ring effect weakens, therefore, with increasing effective height as shown in the bottom panel of the same figure. This fact has been exploited for retrieval of cloud-top-heights from UV scattered radiation (Joiner and Bhartia, 1995; de Beek et al., 2001).

A database of Ring spectra for each scenario that were also defined for the reference intensity and weighting function was created using SCIATRAN (Vountas et al., 1998). The Ring calculation has been, however, limited to the nadir viewing $\left(\operatorname{LOS}=0^{\circ}\right)$ in order to minimize the computational burden. It has been verified that the variation with LOS is negligible and its small variation is accounted for by the fitted Ring amplitude ( $S C D_{\text {Ring }}$ in Eq. 1) that is obtained from the use of the Ring spectrum as an effective absorber.

In order to assess the importance of the ozone dependent contribution to the Raman scattering, a second database was established where the ozone absorption in the Ring radiative transfer calculation was set to zero. About 113 orbits from eight days distributed over the year (29 and 30 March, June, September, and December 1997, respectively) were analysed twice using the two databases. As an example the results for one orbit from 30 December 1997 (orbit 71230132) is shown in Fig. 4. The top panel shows the two retrievals as a function of latitude. Without accounting for ozone dependent contribution to the inelastic Raman scattering a reduction in the retrieved ozone total column is observed. This is expected since the filling-in will broaden the observed ozone absorption and reduce the absorption center peak, thus, resulting in a lowering of the retrieved ozone column. The absolute differences in retrieved ozone is smaller near the 


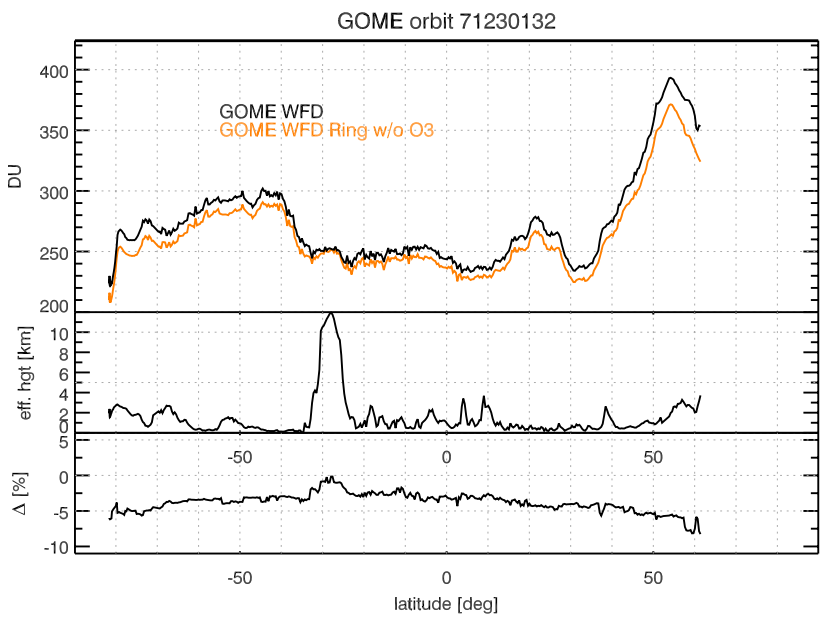

Fig. 4. WFDOAS retrieval of GOME orbit 71230132 (30 December 1997, 13:20 h). Top: The black curve shows the results from retrieval with Ring spectra calculated taking $\mathrm{O}_{3}$ absorption into account and orange line is the result from the fit by neglecting ozone absorption in the Ring calculation, middle panel: effective height retrieved from GOME as a function of latitude. The innertropical convergence zone (ITCZ) is located near $28^{\circ} \mathrm{S}$. Bottom panel: difference between black and orange curves in top panel in percent.

equator $(-3 \%)$ and increases at high latitudes to $(-5 \%)$. This is related to the filling-in that increases with the slant optical path. In the middle panel of Fig. 4 the retrieved effective height is shown and the maximum values are reached in the inner tropical convergence zone near $28^{\circ} \mathrm{S}$. As noted earlier, the Ring effect is strongly reduced at high effective altitudes, here $12 \mathrm{~km}$, and this is also seen in the minimal differences between both retrievals in the ITCZ as shown in the bottom of the same figure.

The error pattern due to the neglect of the ozone dependent contribution to the Ring effect as a function of solar zenith angle, total ozone, and effective height is summarised in Fig. 5. Here the results from all 113 orbits have been included. The error can reach $-50 \mathrm{DU}$ above $500 \mathrm{DU}$ (10\%) and it increases with solar zenith angle and decreases with effective height as discussed earlier. The shadings indicate where the $90 \%$ cumulative probability of all combination of parameters for solar zenith angle and total ozone, one one hand, and secondly, effective height are given. The error varies quite strongly within this shaded region and, is therefore, significant. Even in the case of a fixed ozone scenario used in the Ring calculation, with typical ozone columns of $300 \mathrm{DU}$, errors are still on the order of $-5 \%$ above $500 \mathrm{DU}$. It is clear that the variable ozone dependent contribution in the inelastic Raman scattering has to be properly accounted for in ozone retrieval from backscatter UV.
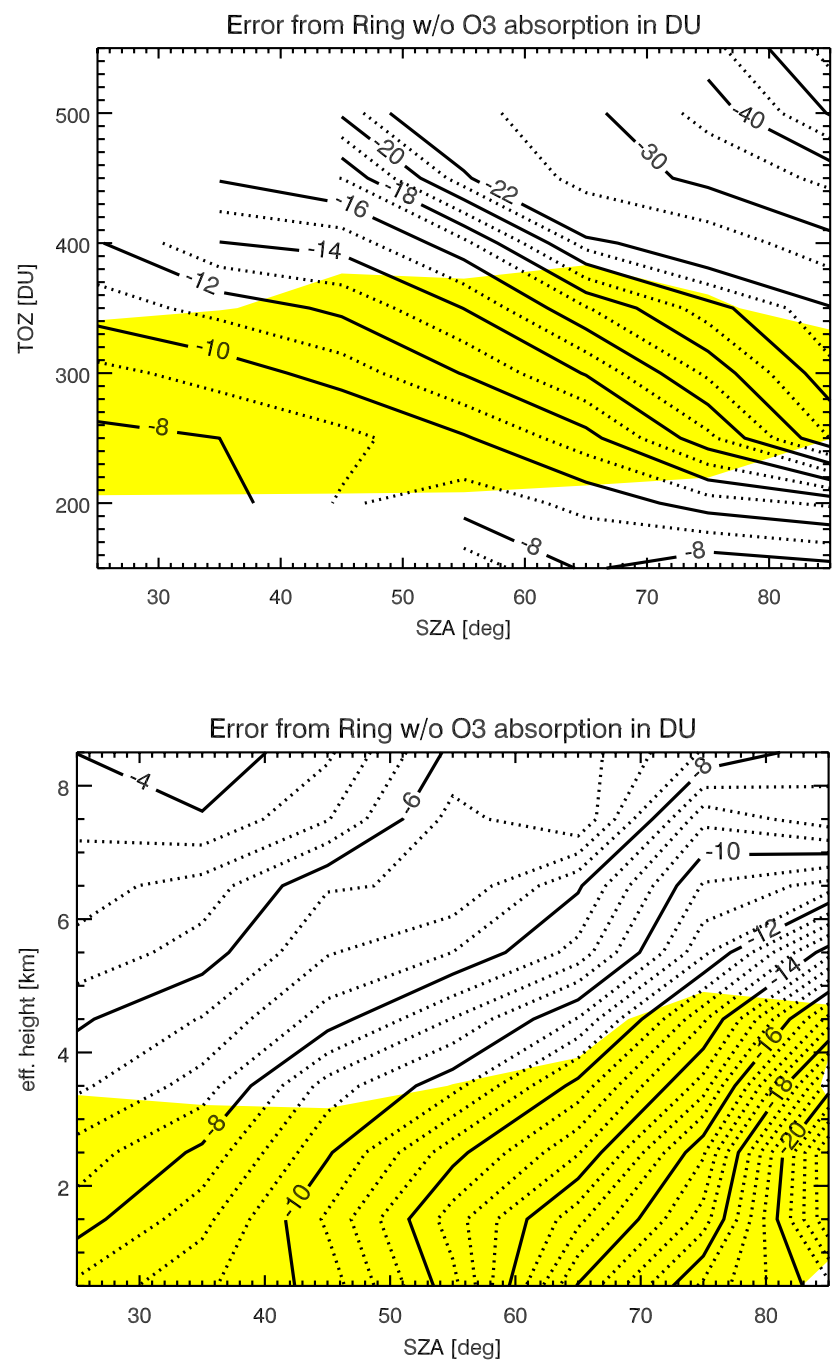

Fig. 5. Differences in retrieved total ozone from the neglect of ozone absorption dependent contribution to inelastic rotational Raman scattering based upon an analysis of 113 GOME orbits from 29 and 30 March, June, September, and December 1997 (eight days). Units are in DU. Top panel: Errors as a function of solar zenith angle and total ozone. Bottom panel: The same but as a function of solar zenith angle and retrieved effective height. The yellow shading indicate the most likely combination of both parameters, solar zenith angle and total ozone (bottom: effective height) for $90 \%$ percent of all individual GOME retrievals (about 205000 ).

\section{Case studies: tropics and mountains}

Total ozone columns in the tropics show lower variability as compared to the higher latitudes. Little dependence of the tropical ozone on effective altitude, albedo, or cloud cover should be observed, if the cloud correction, the albedo retrieval, as well as the GVC corrections are properly carried out. In order to test this, a selected region in the eastern Pacific $\left(20^{\circ} \mathrm{N}\right.$ to $20^{\circ}$ and $120^{\circ} \mathrm{W}$ to $\left.180^{\circ} \mathrm{W}\right)$ from the period 16-18 September 1997 (about 2400 GOME pixels) was 


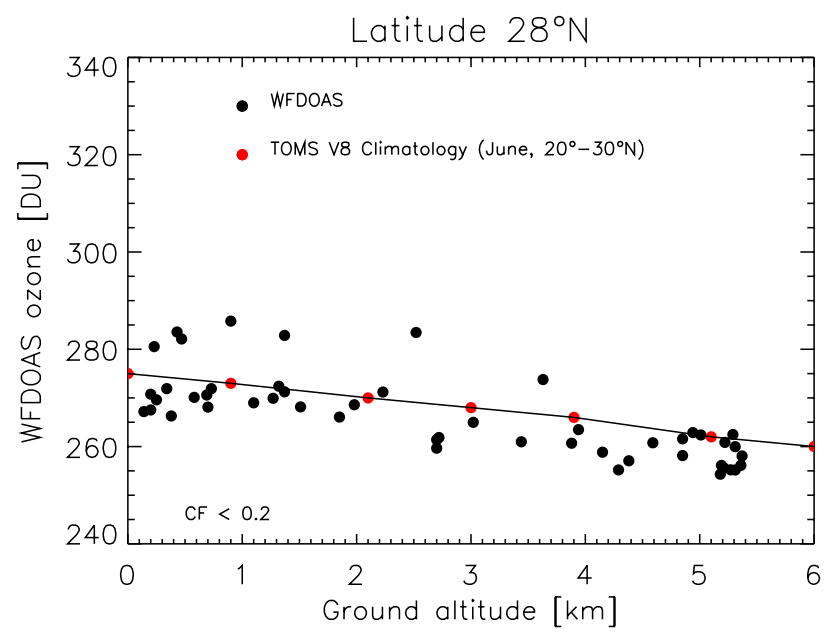

Fig. 6. Influence of ground altitude on ozone retrieval in Himalaya region. GOME data from June 1997 with cloud fraction less than 0.2 are shown as a function of ground altitude for $28^{\circ} \mathrm{N}$ (black dots). Red dots denote the expected decrease in total ozone derived from a TOMS V8 climatological profile for June, $20^{\circ}-30^{\circ} \mathrm{N}$, scaled to a total ozone amount of $275 \mathrm{DU}$.

analysed. No correlation between tropical ozone and effective height, albedo, and cloud cover can be found. The correlation coefficient is below 0.15 in all cases.

For GOME pixels covering high mountains such as the Himalaya, the elevated ground altitude should reduce the retrieved total column. From June 1997 all GOME data from $25^{\circ} \mathrm{N}$ to $40^{\circ}$ and $70-100^{\circ} \mathrm{E}$ with a cloud cover less than 0.2 were analysed. Figure 6 shows the retrieved total ozone columns as a function of altitude. The latitude has been kept fixed at $28^{\circ} \mathrm{N}$ in this plot as ozone and altitude also depend on latitude. Total ozone decreases with increasing height, and the correlation coefficient is -0.76 . In addition, we included the decrease in ozone column with increasing height as it is expected from a climatological ozone profile. We selected the corresponding profile from the TOMS V8 monthly mean climatology for June, $20^{\circ}-30^{\circ} \mathrm{N}$, scaled to a total amount of $275 \mathrm{DU}$. The expected decrease of about $2.5 \mathrm{DU} / \mathrm{km}$ agrees very well with the observed gradient.

\section{Comparison with Version 3 and ground data}

As an example how well WFDOAS is working, comparisons have been made with collocated ground-based Brewer measurements done with a single monochromator Brewer spectrometer at Hohenpeissenberg (MOHp), Germany, $47.8^{\circ} \mathrm{N}$. Collocation criteria for matching GOME and Brewer measurements were a distance of less than $160 \mathrm{~km}$ between the center coordinate of the GOME scene and station and that both measurements took place the same day. In Fig. 7 the time series of the monthly mean differences is shown. The WFDOAS results have a bias of $0.3 \%$ and the RMS scat-
Table 2. Summary of all WFDOAS related error sources applying for total ozone.

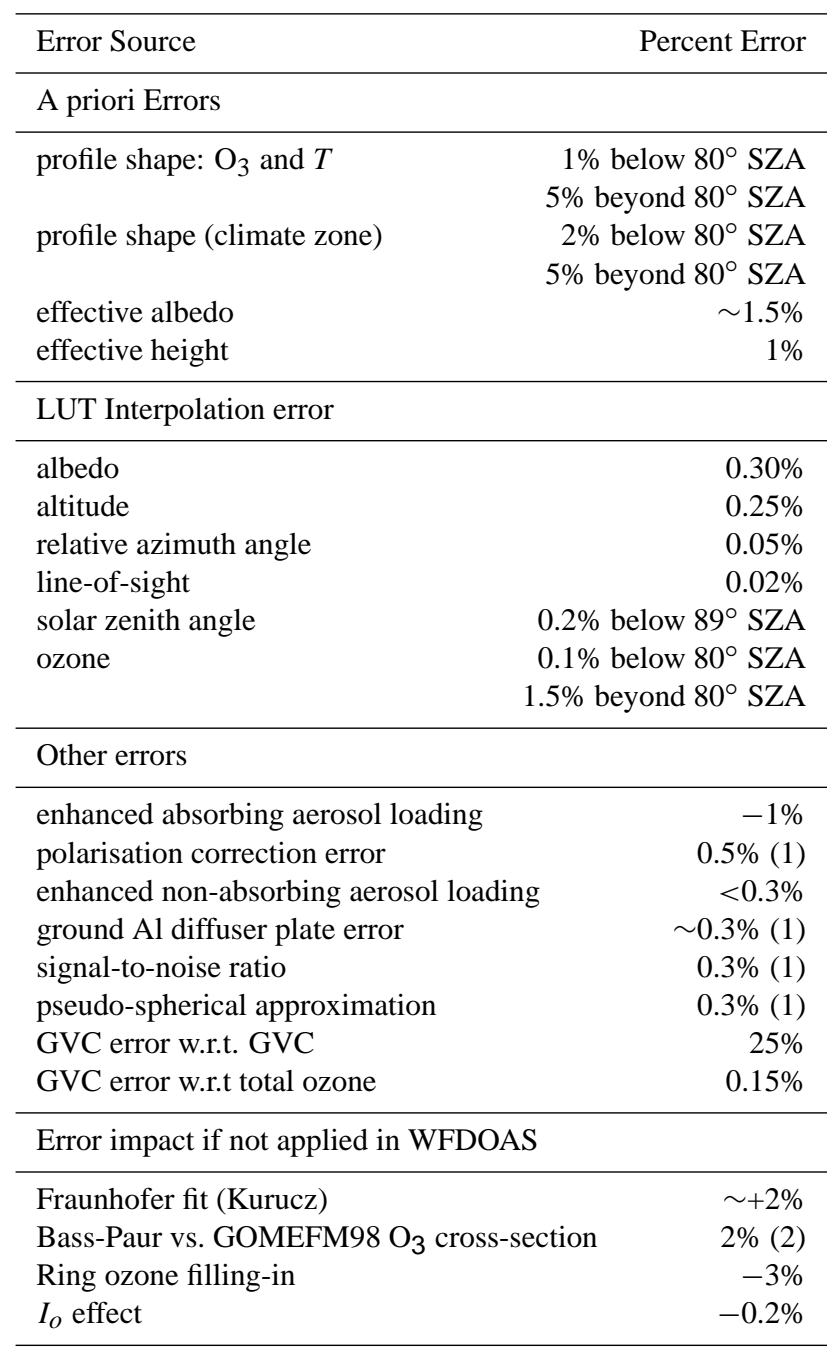

(1) from de Beek et al. (2004)

(2) from Roozendael et al. (2003)

ter is $2.3 \%$ for the daily differences over the seven year period. An almost negligible seasonal variation in the GOMEBrewer differences is observed with amplitudes of $0.5 \%$ over the course of the year. The same comparison using GOME GDP V3 data shows an amplitude of $1.4 \%$ in the differences. A more extensive validation with many ground stations from pole to pole can be found in the companion paper by Weber et al. (2004). This paper confirms the results found in the comparison with Hohenpeissenberg data.

Figure 8 demonstrates how the WFDOAS results have changed compared to GDP V3 for a selected GOME orbit (the same orbit as shown in Fig. 4). Largest differences of up to $5 \%$ are observed at high clouds in the innertropical convergence zone near $28^{\circ} \mathrm{S}$, at high total ozone (near $55^{\circ} \mathrm{N}$ ), and above ice (south of $72^{\circ} \mathrm{S}$ ). This is clearly related to the 


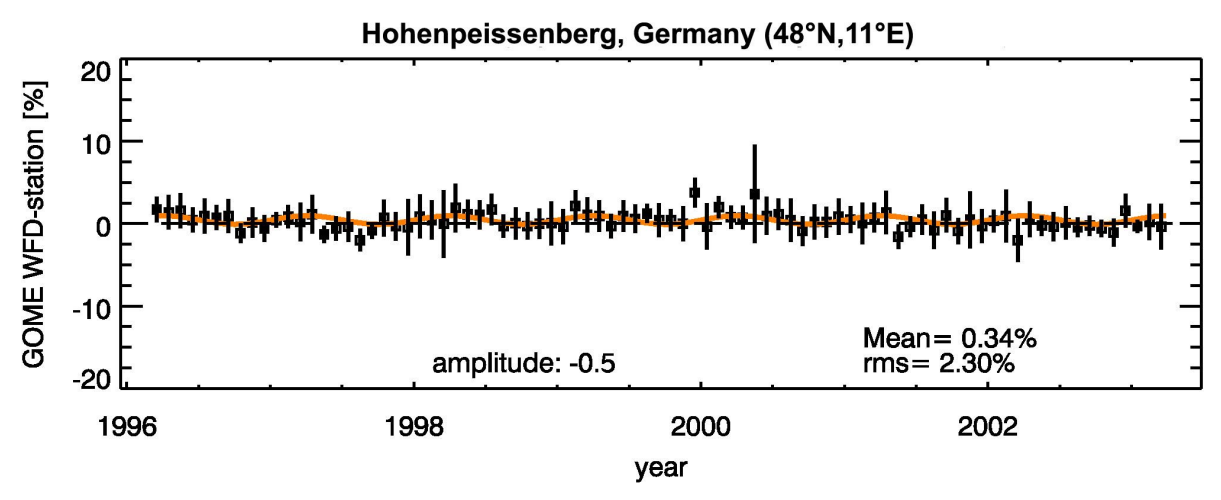

Fig. 7. GOME WFDOAS - Hohenpeissenberg Brewer monthly mean differences from 1996 to 2003 . The error bars indicate the $1 \sigma$ rootmean-square scatter of the monthly mean. Orange curve is a sinusoidal fit to the time series in order to visualise potential seasonal variations in the differences (amplitude: $0.5 \%$ ). The mean bias over the seven year time period is $0.34 \%$ with a $1 \sigma$ rms scatter of $2.3 \%$ in the daily differences.

higher sensitivity of WFDOAS to clouds and scene albedo. On average a difference of about $2-3 \%$ is observed between WFDOAS and GDP V3, which is quite typical for the entire GOME data set.

\section{Error analysis}

In this section the various error sources are summarized that contribute to the overall error of retrieved ozone column, and a global error budget is derived. Table 2 gives an overview on all errors that were identified for WFDOAS. One arrives at a precision of the ozone retrieval on the order of $3 \%$ for the square root of the sum of all individual quadratic errors except for those errors cited in the bottom block of Table 2 (labeled: Error impact if not applied to WFDOAS). The error increases at solar zenith angles above $80^{\circ}$ to at least $5 \%$.

The largest contribution to the overall error comes from the a-priori errors associated with the use of the ozone climatology and simplifying assumptions made in the derivation of effective parameters. The influence of differences between true ozone and temperature profiles and those profiles used for the reference database has been investigated using synthetic radiance spectra. The errors are generally below $2 \%$ if both ozone and temperature weighting function are included in the fit and SZA is below $75^{\circ}$. The influence of an error in the effective albedo input on the retrieved column of ozone is about $1.5 \%$. If an error of $1 \mathrm{~km}$ in effective height can be assumed to be realistic this results in an $1 \%$ error in the ozone column amounts. This has been obtained from retrieval studies with and without effective altitude (ground altitude was used instead) as input.

The look-up-table interpolation errors for effective height, effective albedo, relative azimuth angle, solar zenith angle, line-of-sight, and ozone are well below 0.3\%. Except for ozone interpolation beyond $80^{\circ} \mathrm{SZA}$, the errors may reach $1.5 \%$.

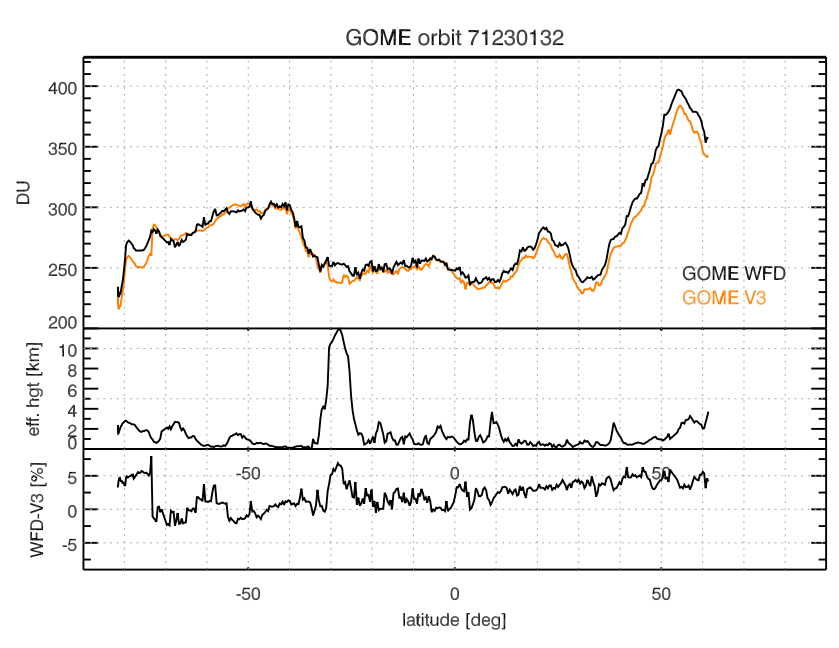

Fig. 8. Comparison of GOME WFDOAS with GOME GDP V3 data for orbit 71230132 (same orbit as shown in Fig. 4). Top: The black curve shows the results from WFDOAS and orange curve the result from GDP V3 in DU. Middle panel: effective height retrieved from GOME as a function of latitude. The innertropical convergence zone (ITCZ) is located near $28^{\circ} \mathrm{S}$. Bottom panel: difference between black and orange curves in top panel in percent.

The ghost vertical column error can be determined by using error estimates for cloud fraction and cloud top height as provided by FRESCO. They are used to investigate the influence on GVC itself and on total ozone. Four orbits from March, June, September, and December 1997 have been analysed and the absolute error is about $0.5 \mathrm{DU}$ on average. The relative error with respect to total ozone is well below $0.2 \%$.

As the effect of aerosols is excluded from the calculation of the WFDOAS reference data base, errors in fitted ozone vertical column may arise for scenes with enhanced aerosol loading. Aerosols which only scatter the light (single 
scattering albedo is close to one) can be accounted for by our concept of using the Lambertian Equivalent Reflectivity instead of surface albedo as input for ozone retrieval. On the other hand, absorbing aerosols are not corrected for with this method. Studies using synthetic test spectra with enhanced non-absorbing aerosol loading (and therefore enhanced TOA reflectivity) have shown that the vertical column error is less than $0.3 \%$ when LER is used as input albedo for the fit. It can be regarded as a first order correction for those types where reflection prevails. Only for absorbing aerosols (volcanic or urban type) the error becomes larger and ozone column may be underestimated by $1 \%$ or more in the case of aerosol optical depths of 0.6 (single scatter albedo 0.81 ) for stratospheric aerosols and 5 (single scatter albedo 0.66 ) for urban aerosols.

The reference database has been derived without using the $I_{o}$ corrected ozone cross section (Aliwell et al., 2002). In order to include this effect, a difference spectrum of the GOME FM 98 cross sections with and without the $I_{o}$ correction has been used as an effective absorber. A reduction in fitting RMS of up to $10 \%$ is observed and ozone columns are reduced by about $0.2 \%$. The sanding of the Aluminium coating on the diffuser plate of the GOME instrument introduces some regular features, which result in spectral features in differential spectra that strongly correlate with absorption features. This error severely affects DOAS retrievals, especially for $\mathrm{NO}_{2}(50 \%$ total column error) and weaker absorbers. For total ozone the error is estimated to be on the order of $0.3 \%$ (de Beek et al., 2004). Additionally, errors related to polarization correction $(0.5 \%)$, and signal-to-noise $(0.3 \%$ in the UV window) occur (de Beek et al., 2004). If the Fraunhofer fitting of the solar reference is not used, the results may differ by $2 \%$. The use of Bass-Paur cross-section (Komhyr et al., 1993) commonly used in retrieval of groundbased measurements in place of the GOME flight model data (Burrows et al., 1999b) may lead to differences of up to $\pm 2 \%$ (Roozendael et al., 2003).

\section{Summary}

A novel type of DOAS total ozone retrieval algorithm, called Weighting Function DOAS, has been developed. It has been designed to retrieve total ozone from backscatter UV satellite instruments such as the Global Ozone Monitoring Experiment. By fitting the wavelength dependent, vertically integrated ozone weighting function, a direct retrieval of vertical column amounts rather than slant columns is possible.

An important element of the new retrieval scheme was the incorporation of other relevant geophysical parameters directly derived from GOME measurements such as cloud parameters using the FRESCO algorithm and the effective albedo. Another important aspect for a correct ozone retrieval is the ozone filling-in as part of the Ring effect, that can lead to systematic underestimation of several percents if not accounted for. The large improvement with this new al- gorithm is to largest extent due to proper treatment of the Ring effect. The introduction of effective height and effective albedo have also, but to a lesser extent, improved the total ozone retrieval.

The precision of the total ozone retrieval is estimated to be better than $3 \%$ for solar zenith angles below $80^{\circ}$ and better than $5 \%$ up to $88^{\circ}$. Comparison with collocated Hohenpeissenberg Brewer measurements showed excellent agreement to within half a percent over eight years of GOME operation. A detailed global validation of WFDOAS with groundbased data is presented elsewhere (Weber et al., 2004) and shows that apart from polar latitudes agreement with groundbased data is to within $1 \%$. The new algorithm is very attractive for application to SCIAMACHY launched in 2002 (Bovensmann et al., 1999), and future instruments like OMI (Ozone Monitoring Instrument, launched in July 2004) (Stammes et al., 1999), and GOME2 on the METOP series.

Acknowledgements. We thank U. Köhler and H. Claude, Meteorological Observatory Hohenpeissenberg, for providing us with their station data. This project was supported in parts by European Space Agency contract 16402/02/I-LG, BMBF grant 7ATF42 (GOMSTRAT) within the AFO2000 national research programme, and EU project EVK2-CT-2001-00133 (CANDIDOZ).

Edited by: T. Koop

\section{References}

Aliwell, S. R., Roozendael, M. V., Johnston, P. V., Richter, A., Wagner, T., Arlander, D. W., Burrows, J. P., Fish, D. J., Jones, R. L., Tornkvist, K. K., Lambert, J.-C., Pfeilsticker, K., and Pundt, I.: Analysis for BrO in zenith-sky spectra: An intercomparison exercise for analysis improvement, J. Geophys. Res., 107(D14), 4199, doi:10.1029/2001JD000329, 2002.

Bodeker, G. E., Scott, J. C., Kreher, K., and McKenzie, R. L.: Global ozone trends in potential vorticity coordinates using TOMS and GOME intercompared against the Dobson network: 1978-1998, J. Geophys. Res., 106(D19), 23 029-23 042, doi:10.1029/2001JD900220, 2001.

Bovensmann, H., Burrows, J. P., Buchwitz, M., Frerick, J., Noel, S., Rozanov, V. V., Chance, K. V., and Goede, A. H. P.: SCIAMACHY - Mission Objectives and Measurement Modes, J. Atmos. Sci., 56, 125-150, 1999.

Buchwitz, M., Rozanov, V. V., and Burrows, J. P.: A near-infrared optimized DOAS method for the fast global retrieval of atmospheric $\mathrm{CH}_{4}, \mathrm{CO}, \mathrm{CO}_{2}, \mathrm{H}_{2} \mathrm{O}$, and $\mathrm{N}_{2} \mathrm{O}$ total column amounts from SCIAMACHY Envisat-1 nadir radiances, J. Geophys. Res., 105, 15 231-15 245, 2000.

Burrows, J. P., Dehn, A., Deters, B., Himmelmann, S., Richter, A., Voigt, S., and Orphal, J.: Atmospheric Remote-Sensing Reference Data from GOME: Part 1. Temperature-Dependent Absorption Cross Sections of $\mathrm{NO}_{2}$ in the 231-794 nm Range, J. Quant. Spectrosc. Rad. Transfer, 60, 1025-1031, 1998.

Burrows, J. P., Weber, M., Buchwitz, M., Rozanov, V. V., Ladstädter-Weissenmayer, A., Richter, A., de Beek, R., Hoogen, R., Bramstedt, K., Eichmann, K.-U., Eisinger, M., and Perner, 
D.: The Global Ozone Monitoring Experiment (GOME): Mission Concept and First Scientific Results, J. Atmos. Sci., 56, 151-175, 1999a.

Burrows, J. P., Richter, A., Dehn, A., Deters, B., Himmelmann, S., Voigt, S., and Orphal, J.: Atmospheric Remote-Sensing Reference Data from GOME: Part 2. Temperature-dependent absorption Cross Sections of $\mathrm{O}_{3}$ in the 231-794 nm range, J. Quant. Spectrosc. Rad. Transfer, 61, 509-517, 1999b.

Chance, K. and Spurr, R. J. D.: Ring effect studies: Rayleigh scattering, including molecular parameters for rotational Raman scattering and the Fraunhofer spectrum, Appl. Opt., 36, 52245230, 1997.

Coldewey-Egbers, M., Weber, M., Buchwitz, M., and Burrows, J. P.: Application of a modified DOAS method for ozone retrieval from GOME data at high polar latitude, Adv. Space Res., 34, 749-753, 2004.

de Beek, R., Vountas, M., Rozanov, V. V., Richter, A., and Burrows, J. P.: The Ring Effect in the cloudy atmosphere, Geophys. Res. Lett., 28, 721-724, 2001.

de Beek, R., Weber, M., Rozanov, V. V., Rozanov, A., Richter, A., and Burrows, J. P.: Trace gas column retrieval - An error study for GOME-2, Adv. Space Res., 34, 727-733, 2004.

Fioletov, V. E., Bodeker, G. E., Miller, A. J., McPeters, R. D., and Stolarski, R.: Global and zonal total ozone variations estimated from ground-based and satellite measurements: 1964-2000, J. Geophys. Res., 107 (D22), 4647, doi:10.1029/2001JD001350, 2002

Fish, D. J. and Jones, R. L.: Rotational Raman scattering and the Ring effect in zenith-sky spectra, Geophys. Res. Lett., 22, 811814,1995

GDP V3 VALREPORT: ERS-2 GOME GDP 3.0 Implementation and Delta Validation Report, Technical Note ERSE-DTEXEOAD-TN-02-0006, Issue 1.0, edited by: Lambert, J.-C., November 2002, see also: http://earth.esrin.esa.it/pub/ESA DOC/GOME/gdp3/gdp3.htm, 2002.

Grainger, J. F. and Ring, J.: Anomalous Fraunhofer line profiles, Nature, 193, 762-762, 1962.

Herman, J. R. and Celarier, E. A.: Earth surface reflectivity climatology at 340-380 nm from TOMS data, J. Geophys. Res., 102, $28003-28011,1997$.

Joiner, J. and Barthia, P. K.: Rotational Raman scattering (Ring effect) in satellite backscatter ultraviolet measurements, Appl. Opt., 34, 4513-4525, 1995a.

Joiner, J. and Bhartia, P. K.: The determination of cloud pressures from rotational Raman scattering in satellite backscatter ultraviolet measurements, J. Geophys. Res., 100, 23 019-23 026, 1995 b.

Kattawar, G. W., Young, A. T., and Humphries, T. J.: Inelastic scattering in planetary atmospheres, I. The Ring effect without aerosols, Astrophys. J., 243, 1049-1057, 1981.

Koelemeijer, R. B. A., Stammes, P., Hovenier, J. W., and de Haan, J. F.: A fast method for retrieval of cloud parameters using oxygen A-band measurements from the Global Ozone Monitoring Experiment, J. Geophys. Res., 106, 3475-3496, 2001.

Koelemeijer, R. B. A., de Haan, J. F., and Stammes, P.: A database of spectral surface reflectivity in the range $335-772 \mathrm{~nm}$ derived from 5.5 years of GOME observations, J. Geophys. Res., 108(D2), 4070, doi:10.1029/2002JD002429, 2003.
Komhyr, W. D., Mateer, C. L., and Hudson, R. D.: Effective BassPaur 1985 ozone absorption coeffcients for use with Dobson ozone spectrophotometers, J. Geophys. Res., 98, 20 451-20 465, 1993.

Kurucz, R. L., Furenlid, I., Brault, J., and Testerman, L.: Solar flux atlas from $296 \mathrm{~nm}$ to $1300 \mathrm{~nm}$, National Solar Observatory, Sunspot, New Mexico, 1984.

Lamsal, L. N., Weber, M., Tellmann, S., and Burrows, J. P.: Ozone column classified climatology of ozone and temperature profiles based on ozonesonde and satellite data, J. Geophys. Res., 109, D20304, doi:10.1029/2004JD004680, 2004.

Richter, A., Wittrock, F., Eisinger, M., and Burrows, J. P.: GOME Observations of Tropospheric $\mathrm{BrO}$ in Northern Hemispheric Spring and Summer 1997, Geophys. Res. Lett., 25, 2683-2686, 1998.

Roozendael, M., Soebijanta, V., Fayt, C., and Lambert, J.-C.: Investigation of DOAS issues affecting the accuracy of the GDP version 3.0 total ozone product, unpublished manuscript, see Chapter VI of http://earth.esrin.esa.it/pub/ESA_DOC/GOME/gdp3/ gdp3.htm, 2003.

Rozanov, V. V., Diebel, D., Spurr, R. J. D., and Burrows, J. P.: GOMETRAN: A Radiative Transfer Model for the Satellite Project GOME, The Plane-Parallel Version, J. Geophys. Res., 102, 16683-16695, 1997.

Rozanov, V. V., Kurosu, T., and Burrows, J. P.: Retrieval of Atmospheric Constituents in the UV/visible: A new Analytical Approach to Calculating Weighting Functions, J. Quant. Spectrosc. Rad. Transfer, 60, 277-299, 1998.

Sioris, C. E. and Evans, W. F. J.: Filling in of Fraunhofer and gasabsorption lines in sky spectra as caused by rotational Raman scattering, Appl. Opt., 38, 2706-2713, 1999.

Slijkhuis, S., van Bargen, A., Thomas, W., and Chance, V. K.: Calculation of Undersampling correction spectra for DOAS spectral fitting, in ESAMS'99 - European Symposium on Atmospheric Measurements from Space, edited by: ESA, ESA WPP-161, 563-569, ESA, Noordwijk, The Netherlands, 1999.

Solomon, S., Schmeltekopf, A. L., and Sanders, R. W.: On the interpretation of zenith-sky absorption measurements, J. Geophys. Res., 92, 8311-8319, 1987.

Stammes, P., Levelt, P., de Vries, J., Visser, H., Kruizinga, B., Smorenburg, C., Leppelmeier, G., and Hilsenrath, E.: Scientific requirements and optical design of the Ozone Monitoring Instrument on EOS-CHEM, in: Proceedings of SPIE Conference on Earth Observing Systems IV, July 1999, Denver, Colorado, USA, vol. SPIE 3750, 221-232, 1999.

Vountas, M., Rozanov, V. V., and Burrows, J. P.: Ring Effect: Impact of Rotational Raman Scattering on Radiative Transfer in Earth's Atmosphere, J. Quant. Spectrosc. Radiat. Transfer, 60, 943-961, 1998.

Weber, M., Lamsal, L. N., Coldewey-Egbers, M., Bramstedt, K., and Burrows, J. P.: Pole-to-pole validation of GOME WFDOAS total ozone with groundbased data, Atmos. Chem. Phys. Discuss., 4, 6909-6941, 2004,

\section{SRef-ID: 1680-7375/acpd/2004-4-6909.}

Wellemeyer, C. G., Taylor, S. L., Seftor, C. J., McPeters, R. D., and Bhartia, P. K.: A correction for the Total Ozone Mapping Spectrometer profile shape errors at high latitude, J. Geophys. Res., 102, 9029-9038, 1997. 